\title{
The role of FOXO3 in DNA damage response in thyrocytes
}

\author{
Antje Klagge, Carl Weidinger, Kerstin Krause, Beate Jessnitzer, \\ Monika Gutknecht and Dagmar Fuhrer
}

Clinic of Endocrinology and Nephrology, Department of Internal Medicine, Neurology and Dermatology, University of Leipzig, Liebigstraße 18, 04103 Leipzig, Germany

(Correspondence should be addressed to D Fuhrer; Email: dagmar.fuehrer@uk-essen.de)

\begin{abstract}
Members of the forkhead box-O (FOXO) transcription factors family play an important role in stress defence. $\mathrm{FOXO} 3$ deregulation has recently been identified as a hallmark of thyroid carcinogenesis. In this study, we explore the role of FOXO3 in defence of oxidative stress in normal thyrocytes. Stable rat thyroid cell lines were generated expressing either the human wildtype FOXO3, a constitutively activating FOXO3 mutant, or the empty control vector. Cell clones were characterised for proliferation, function and morphology. Hydrogen peroxide and UV irradiation were used to induce oxidative stress. Changes in FOXO3 activity, induction of cell cycle arrest or apoptosis and kinetics of DNA damage repair were analysed. Upregulation of FOXO3 in thyrocytes resulted in decreased proliferation and changes in morphology, but did not affect differentiation. Hydrogen peroxide stimulated the expression of the FOXO3 target genes growth arrest and DNA damage-inducible protein $45 \alpha$ (Gadd $45 \alpha)$ and Bcl-2 interacting mediator of cell death (BIM) and induced programmed cell death in cells with overexpression of the human wildtype FOXO3. In contrast, UV irradiation resulted in a distinct cellular response with activation of FOXO3-C-Jun-N-terminal kinase-Gadd45 $\alpha$ signalling and induction of cell cycle arrest at the $\mathrm{G}_{2}-\mathrm{M}$-checkpoint. This was accompanied by FOXO3-induced DNA damage repair as evidenced by lower DNA breaks over time in a comet assay in FOXO3 cell clones compared with control cells. In conclusion, $\mathrm{FOXO} 3$ is a pivotal relay in the coordination of the cellular response to genotoxic stress in the thyroid. Depending on the stimulus, FOXO3 induces either cell cycle arrest or apoptosis. Conversely, FOXO3 inactivation in thyroid cancers is consistent with genomic instability and loss of cell cycle control.
\end{abstract}

Endocrine-Related Cancer (2011) 18 555-564

\section{Introduction}

Clonal thyroid tumours arise form genetic alterations, e.g. point mutations such as RAS or BRAF or gene rearrangements such as rearranged in transfection/ papillary thyroid carcinomas (RET/PTC) or PAX8/ PPAR $\gamma$ (Knauf \& Fagin 2009). Among the most prominent factors that may contribute to mutagenesis in thyrocytes are reactive oxygen species (ROS) and radiation. The thyroid gland produces large amounts of hydrogen peroxide during thyroid hormone synthesis, which creates a potentially mutagenic environment through generation of ROS (Krohn et al. 2007, Song et al. 2007). At the same time, the thyroid gland contains a potent repertoire of catalytic enzymes involved in hydrogen peroxide detoxification and antioxidative defence (Song et al. 2007). Cold thyroid nodules (CTN) are characterised by the upregulation of several proteins of the generation of hydrogen peroxide and detoxification system (Krause et al. 2007). Moreover, increased formation of 8-oxo-guanidine DNA adducts was detected in CTN and could suggest an increased potential for genotoxicity and mutagenesis (Krause et al. 2007, Karger et al. manuscript submitted). In addition, iodine deficiency is the most prominent environmental cause of thyroid nodule formation (Krohn et al. 2005). It is associated with upregulation of antioxidative enzymes, e.g. superoxide dismutase 3 , glutathione peroxidase 4 and peroxiredoxins 3 and 5, and causes DNA modifications in thyrocytes (Maier et al. 2007). Radiation is another 
known environmental risk factor for nodular thyroid disease and is a characteristic pathogen for the evolution of papillary thyroid cancers (Sinnott et al. 2010). Radiation induces DNA double-stranded breaks leading to RET/PTC fusion genes in the Chernobyl papillary thyroid cancers as elegantly demonstrated by Nikiforova et al. (2000).

Forkhead box-O (FOXO) transcription factors represent an important family of tumour suppressor proteins that regulate the expression of genes involved in cell differentiation, resistance to oxidative stress, DNA damage repair, cell cycle arrest and apoptosis (Brunet et al. 1999, Huang \& Tindall 2007, Myatt \& Lam 2007, Weidinger et al. 2008). The function of FOXOs predominantly depends on signalling pathways that influence the subcellular localisation and activity of FOXOs and regulate specific FOXO target gene transcription. For example, activation of the phosphatidylinositol 3-kinase (PI3K)/AKT pathway through growth factors leads to FOXO3 phosphorylation and inactivation by cytoplasmic sequestration (Brunet et al. 1999). In contrast, $\mathrm{H}_{2} \mathrm{O}_{2}$ exposure results in FOXOs activation through c-JunN-terminal kinases (JNKs; Essers et al. 2004).

We have recently demonstrated that inactivation of FOXO3 is a hallmark of thyroid carcinogenesis and have shown that cytoplasmic accumulation of FOXO3 correlates with increased p-AKT expression in thyroid malignancies linked to constitutive activation of the PI3K/AKT pathway (Karger et al. 2009).

In this study, we address the role of human FOXO3 as a cellular relay that coordinates the response to genotoxic stress and DNA damage in the thyroid. To this aim, we analysed the response to oxidative stress due to hydrogen peroxide stimulation or UV irradiation in rat thyroid cells (FRTL5 cells) stably expressing the wild-type FOXO3 or a constitutively activating mutant of FOXO3, which cannot be inactivated through AKT phosphorylation. We show that in normal thyrocytes, FOXO3 is a pivotal player in oxidative stress defence ensuring cell cycle control and DNA damage repair.

\section{Materials and methods}

\section{Cells culture conditions}

\section{Cell culture of FRTL5 cells}

Follicular rat thyroid cells (FRTL5 cells) provided by Prof. R DiLauro, Naples, Italy, were cultured in a 2:1:1 mixture of DMEM:Ham's F12:MCDB104 (all from Gibco Life Technologies) supplemented with 5\% (v/v) newborn calf serum (Gibco Life Technologies), $10 \mu \mathrm{g} / \mathrm{ml}$ insulin, $0.4 \mu \mathrm{g} / \mathrm{ml}$ hydrocortisone (Calbiochem, San
Diego, CA, USA), $45 \mu \mathrm{g} / \mathrm{ml}$ ascorbic acid (Sigma), $5 \mu \mathrm{g} / \mathrm{ml}$ transferrin (Calbiochem) and $5 \mathrm{mU} / \mathrm{ml}$ bovine TSH (Sigma-Aldrich). Cell culture medium was changed every 2 days and cells were passaged at $80 \%$ confluency.

\section{Plasmids, nucleofection and generation of stable FRTL5 cell lines}

FRTL5 $\left(1 \times 10^{6}\right)$ cells were transfected with a pcDNA3.1/V5-HisA plasmid (Invitrogen) containing a geneticin resistance gene and the human wild-type FOXO3 or a constitutively activating triple mutant of FOXO3 (FOXOA3). pcDNA3.1/V5-HisA plasmid constructs were generated by HindIII/ApaI subcloning from the pECE-FKHRL1 FOXO3 and FOXOA3 constructs generously provided by Prof. P Coffer, UMC Utrecht, The Netherlands. The empty pcDNA3.1/V5-HisA plasmid served as control.

Transfection was performed using $100 \mu \mathrm{l}$ nucleofector solution $\mathrm{V}$ and program A-030 of the nucleofection system (Lonza Cologne GmbH, Cologne, Germany). Two days after transfection, geneticin (Gibco Life Technologies) selection was started. After four weeks of geneticin selection, colonies were picked and seeded in new 6-well culture dishes. Cell clones were grown under continued geneticin selection and positive clones were tested by RT-PCR with a FOXO3-specific forward primer and a vector-specific reverse primer. PCR was carried out using $4 \mu \mathrm{l} \mathrm{cDNA}, 200 \mu \mathrm{M}$ of each dNTP, 5 pmol of each primer (forward: 5'-TTGATGTCTCAGGCCAGCACCG-3' $3^{\prime}$ and reverse: $5^{\prime}$-GATAGGCTTACCTTCGAAGG-3' ${ }^{\prime}$ ), $1 \mathrm{mM} \mathrm{MgCl}_{2}$ and 1 unit Taq polymerase (Taq DNA Polymerase Kit; Qiagen) and the following PCR conditions: initial denaturation at $95^{\circ} \mathrm{C}$ for $5 \mathrm{~min}$, followed by 34 cycles of $95^{\circ} \mathrm{C}$ for $30 \mathrm{~s}, 50{ }^{\circ} \mathrm{C}$ for $30 \mathrm{~s}, 72{ }^{\circ} \mathrm{C}$ for $1 \mathrm{~min}$ and a final elongation at $72{ }^{\circ} \mathrm{C}$ for $10 \mathrm{~min}$. The amplified PCR products were visualised on a $1.5 \%(\mathrm{w} / \mathrm{v})$ agarose gel stained with ethidium bromide.

\section{Hydrogen peroxide stimulation}

A dilution of $0.4 \mathrm{mM} \mathrm{H}_{2} \mathrm{O}_{2}$ (Roth) was prepared in PBS immediately before use. Medium was changed to PBS, and FRTL5 cell clones (FOXO3, FOXOA3 and empty vector control) were exposed to $\mathrm{H}_{2} \mathrm{O}_{2}$ to investigate the effects on gene expression $(4 \mathrm{~h})$, cell cycle and apoptosis (24 h; Karger et al. 2009).

\section{UV irradiation}

FRTL5 cell clones (FOXO3, FOXOA3 and empty vector control) were exposed to a single dose of UV irradiation at a dose of 0.001 or $0.1 \mathrm{~J} / \mathrm{cm}^{2}$ at room temperature. To determine the effects on gene 
expression or cell cycle and apoptosis, FRTL5 cell clones were incubated at $37{ }^{\circ} \mathrm{C}$ for $8 \mathrm{~h}$ and $48 \mathrm{~h}$ after irradiation with $0.001 \mathrm{~J} / \mathrm{cm}^{2}$. For the comet assay, FRTL5 cell clones (FOXO3, empty vector control) were incubated for 30, 60 and 120 min after irradiation with $0.1 \mathrm{~J} / \mathrm{cm}^{2}$.

\section{LY294002 stimulation}

FRTL5 cell clones (FOXO3, FOXOA3 and empty vector control) were incubated with $0.02 \mathrm{mM}$ LY294002 (Calbiochem), an inhibitor of the PI3K, for $4 \mathrm{~h}$.

\section{Investigation of proliferation, morphology and function in FRTL5 cells}

\section{Growth curves}

FRTL5 cell clones (FOXO3, FOXOA3 and empty vector control) were plated at a density of $2.5 \times 10^{4}$ cells/well in 12-well dishes and were maintained in full growth medium. Cell numbers were determined on days 3, 6, 9 and 12 by cell counting using a Neubauer chamber.

\section{Morphology}

FRTL5 cell clones (FOXO3, FOXOA3 and empty vector control) were plated at a density of $1.5 \times 10^{5}$ cells/well in 6-well dishes containing cover slips and were grown for 5 days. To identify different morphological appearances, FRTL5 cell clones were fixed with $3.7 \%(\mathrm{v} / \mathrm{v})$ formaldehyde (Roth) and stained with haematoxylin and eosin (DAKO Cytomation, Hamburg, Germany) for $1 \mathrm{~min}$. Morphology was analysed by light microscopy.

\section{RNA extraction and real-time $R T-P C R$}

RNA extraction was performed using TRIzol reagent (Invitrogen). RNA cleanup was performed using the RNeasy Mini Kit 50 (Qiagen). cDNA synthesis was performed at $37^{\circ} \mathrm{C}$ for 60 min with $1 \mu \mathrm{g}$ RNA using random hexamer primers and Moloney murine leukaemia virus reverse transcriptase (GibcoBRL, Karlsruhe, Germany). Real-time RT-PCR was performed using the LightCycler System and LightCycler-DNA Master SYBR Green I Kit (Roche) according to the manufacturer's instructions. Measurement of gene expression was performed for FOXO3 target genes growth arrest and DNA damage-inducible protein $45 \alpha$ (Gadd45 $\alpha$ ), Bcl-2 interacting mediator of cell death (BIM) and $\mathrm{p} 27^{\mathrm{KIP} 1}$ and for thyroid differentiation genes NIS and TPO using rat-specific primers (primer sequences and PCR conditions are available on request). Rs6 mRNA was chosen as an internal standard. The LightCycler Software calculated the threshold cycles. Each sample was measured in duplicates and real-time RT-PCR was repeated at least thrice. Fold upregulation or downregulation of mRNA expression was determined by the use of the $\Delta \Delta C_{\mathrm{T}}$-method (Karger et al. 2009). For statistics (Mann-Whitney $U$ test), the SPSS version 11.0 was used (SPSS, Inc., Chicago, IL, USA) and $P$ values $<0.05$ were considered significant.

\section{Western blotting}

FRTL5 cell clones (FOXO3, FOXOA3 and empty vector controls) were plated at a density of $2.5 \times 10^{5}$ cells/well in 6-well dishes and were grown until $80 \%$ confluency. Protein extraction was performed in NP-40 lysis buffer containing $1 \mathrm{mM}$ sodium orthovanadate and $1 \times$ complete protease inhibitor (Roche). Samples were subjected to standard western blotting. Briefly, blots were probed with antiphospho-FOXO3 (Thr32, 1:1000 overnight), anti-total FOXO3 (1:1000 overnight), antiphospho-JNK (Thr183/Tyr185, 1:1000 overnight), anti-total JNK (1:500 overnight), anti- $\gamma$ H2AX (Ser139, 1:1000 overnight), anti-total H2AX (1:1000 overnight; all antibodies from Cell Signaling Technology, Charlottesville, VA, USA) and anti- $\beta$ actin (1:500 overnight, Sigma-Aldrich). Binding was demonstrated using an antirabbit IgG-HRP-linked antibody $(1: 3000,1 \mathrm{~h}$ at room temperature, Cell Signaling Technology) and the ECL chemiluminescence detection system (Krause et al. 2007).

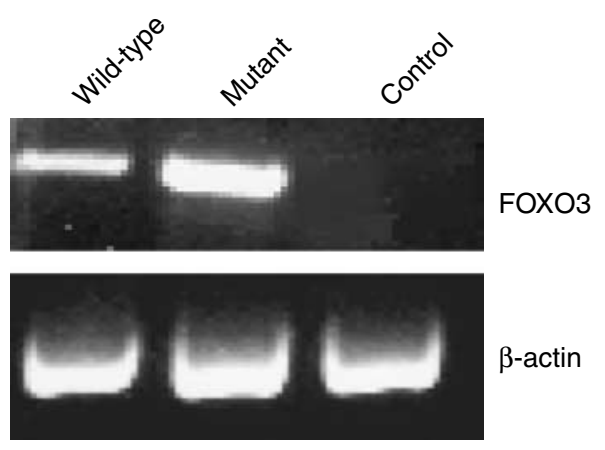

Figure 1 Generation of stable FRTL5 cell clones with FOXO3 overexpression or expression of a constitutively activating FOXOA3 mutant. FRTL5 cells were transfected with a pcDNA3.1/V5 plasmid expressing the human wild-type FOXO3, a constitutively activating triple mutant of $\mathrm{FOXO} 3$ (FOXOA3) or the empty pcDNA3.1/V5 plasmid (control). Stable clones were obtained by geneticin selection. Positive clones were tested by RT-PCR with a FOXO3-specific forward primer and a vectorspecific reverse primer. The amplified PCR products were visualised on a $1.5 \%$ agarose gel stained with ethidium bromide. Wild-type, FOXO3; mutant, FOXOA3; control, empty pcDNA3.1/V5-HisA vector. 


\section{Apoptosis analysis}

FRTL5 cell clones (FOXO3, FOXOA3 and empty vector controls) were plated at a density of $2.5 \times 10^{5}$ cells/well in 6-well dishes. Twenty-four hours after treatment, cells were trypsinised and double stained with Annexin V-Cy 5 Reagent/PI (Biovision, Inc., Mountain View, CA, USA) in Annexin $\mathrm{V}$ binding buffer. Apoptotic (Annexin $\mathrm{V}$ positive) and necrotic (PI positive) cells were detected by FACS analysis using a Laser Scanning Cytometer LSR2 (CompuCyte Corp., Westwood, MA, USA). Data were analysed by using the FACSDiva Software version 5.0 (BD Bioscience, San Jose, CA, USA). The same gates were used for unstimulated and stimulated cells.

\section{Cell cycle analysis}

FRTL5 cell clones were plated at a density of $2.5 \times 10^{5}$ cells/well in 6-well dishes. Twenty-four hours after treatment, nuclei were harvested using citric acid/ Tween solution and fixed in ice-cold ethanol for at least $24 \mathrm{~h}$. Nuclei were washed and stained with propidium iodide (Sigma). At least 10000 events were collected and analysed by FACS analysis.
Analysis of DNA damage repair by comet assay

FRTL5 cell clones were plated at a density of $2 \times 10^{5}$ cells/well in 6-well dishes. After treatment, cells were trypsinised and embedded in $1 \%(\mathrm{w} / \mathrm{v})$ agarose on a glass slide. Cells were maintained in lysis buffer $(2.5 \mathrm{M}$ $\mathrm{NaCl}, 0.1 \mathrm{M}$ EDTA, $10 \mathrm{mM}$ Tris, and $0.1 \%$ (v/v) Triton X-100) for $1 \mathrm{~h}$ at $4{ }^{\circ} \mathrm{C}$. Afterwards, slides were incubated with alkaline electrophoresis buffer $(10 \mathrm{M}$ $\mathrm{NaOH}$ and $200 \mathrm{mM}$ EDTA) for 40 min to allow DNA to unwind. Subsequently, electrophoresis was carried out for $30 \mathrm{~min}$ at $300 \mathrm{~mA}$. Thereafter, cells were neutralised thrice (0.4 M Tris, $\mathrm{pH} 7.5)$ and stained with ethidium bromide. For quantification, 100 randomly selected comets on each gel were classified according to the relative intensity of fluorescence in the tail and given a value either of $0,1,2,3$ or 4 , from undamaged (represented by 0 ) to maximally damaged (represented by 4; Collins 2004). Accordingly, the total score for each gel could vary from 0 to $400 \mathrm{AU}$ reflecting the level of DNA damage (sum of single- and doublestranded DNA breaks). For statistics (ANOVA test), the SPSS version 11.0 was used (SPSS, Inc.) and $P$ values $<0.05$ were considered significant.

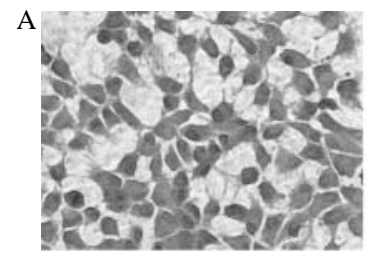

D

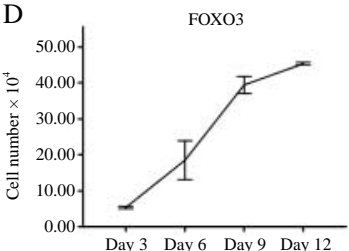

$\mathrm{E}$

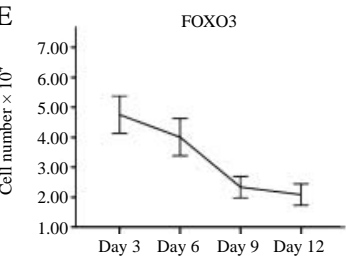

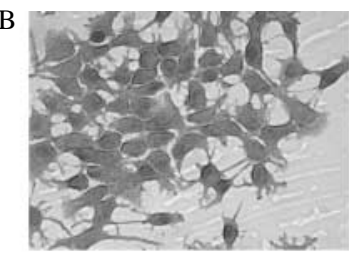

FOXOA3

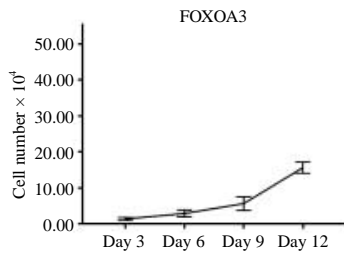

FOXOA3

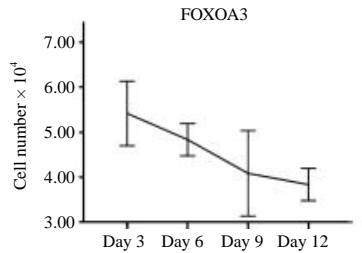

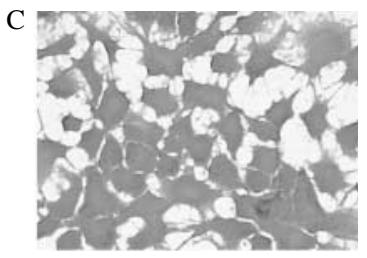
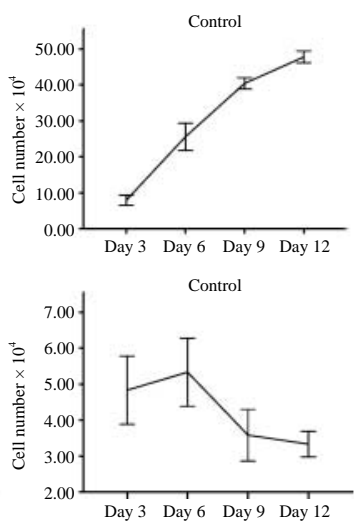

Figure 2 FOXO3 expression in FRTL5 cells results in altered morphology and reduced proliferation. FRTL5 cells stably expressing the wild-type FOXO3 (A), a constitutively activating FOXOA3 mutant (B) or the empty vector as controls (C) were stained with haematoxylin and eosin. FRTL5 cells with wild-type FOXO3 or FOXOA3 mutant expression showed a similar morphology pictured by a round cell body with a clear nucleus and few cytoplasmic extensions. In contrast, control cells showed the characteristic 'FRTL5 cell appearance' with a more rectangular cell body with no clear nucleus and star-shaped extensions. Stable FRTL5 cell clones were plated at a density of $2.5 \times 10^{4}$ cells/well in 12-well dishes and cell numbers were determined on days $3,6,9$, and 12 by cell counting. Growth curves were carried out in full hormone culture medium (D) and under stimulation with LY294002 to block PI3K signalling (E). The highest proliferation rate was observed in control cells transfected with the empty vector. The lowest proliferation rate was found in the FOXOA3 mutant FRTL5 cells, in which compared with wild-type FOXO3 FRTL5 cells, proliferation was reduced by two-thirds. LY294002 treatment resulted in decreased proliferation in all cell clones, whereby FOXOA3 cells exhibited the least decrease (since the FOXOA3 mutant is resistant to PI3K targeting). 


\section{Results}

Characterisation of FRTL5 cell clones with stable overexpression of wild-type FOXO3 and mutant FOXOA3

After 4 weeks of geneticin selection, stable expression of human wild-type FOXO3 (FOXO3) and a constitutively activating triple mutant of FOXO3 (FOXOA3), which cannot be inactivated through AKT phosphorylation, was determined using RT-PCR with FOXO3specific primers. Amplified PCR products were visualised on an agarose gel (Fig. 1) and presence of human FOXO3 was demonstrated by directed sequencing. For further analysis, stable FRTL5 cell clones showing comparable levels of human wild-type FOXO3 and mutant FOXO3 mRNA expression were selected. First, the expression of thyroid differentiation markers NIS and TPO was investigated by quantitative real-time RT-PCR in the FOXO3 and FOXOA3 mutant cell clones using FRTL5 cells with stable expression of the empty vector as control. No difference in transcript levels of NIS and TPO was found for the wild-type FOXO3 or mutant FOXOA3 clones compared with control FRTL5 cells. In a next step, morphological changes caused by stable expression of FOXO3 were studied after haematoxylin and eosin staining. FRTL5 cells with wild-type FOXO3 or FOXOA3 mutant expression showed a similar morphology characterised by a round cell body with a clear nucleus and few cytoplasmic extensions (Fig. 2A and B). In contrast, control cells showed the characteristic 'FRTL5 cell appearance' with a rectangular-shaped cell body with no clear nucleus and star-shaped extensions (Fig. 2C). Furthermore, we examined differences in cellular growth by obtaining growth curves over 12 days (Fig. 2D). In full growth medium, the highest proliferation rate was observed in control cells transfected with the empty vector followed by FRTL5 cells with wild-type FOXO3 overexpression. The lowest proliferation rate was found in the FOXOA3 mutant FRTL5 cells in which, compared with wild-type FOXO3 cells, proliferation was reduced by two-thirds (Fig. 2D). Moreover, cell clones were treated with the PI3K inhibitor LY294002 that inhibits PI3K/AKT-driven FOXO3 inactivation. All FRTL5 cell clones illustrated a decrease in cellular proliferation over 12 days (Fig. 2E). Thereby, cells bearing the constitutively active FOXOA3 mutant, which cannot be inactivated by PI3K and control cells, exhibited the least decrease in growth while FRTL5 cells with overexpression of wild-type FOXO3 exhibited the most intense decrease in growth.
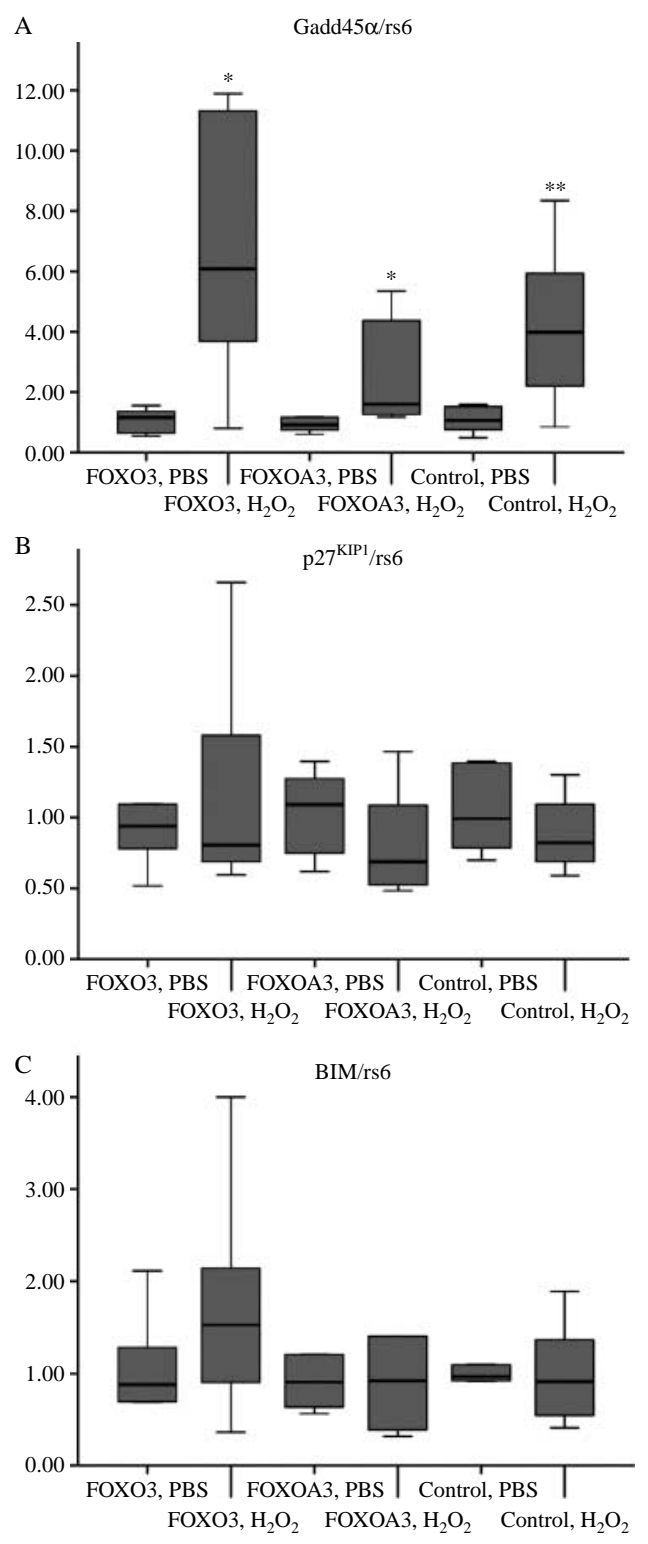

Figure 3 Gene expression in FOXO3 FRTL5 cell clones after $\mathrm{H}_{2} \mathrm{O}_{2}$ stimulation. Box plots showing median and distribution of Gadd $45 \alpha(\mathrm{A}), \mathrm{p}^{\mathrm{KIP1}}(\mathrm{B})$ and BIM (C) mRNA expression in FRTL5 cell clones with stable expression of FOXO3, the FOXOA3 mutant or the empty vector (controls). mRNA expression was normalised to $r s 6$ mRNA expression and expression levels of $\mathrm{H}_{2} \mathrm{O}_{2}$-stimulated cells were corrected for the relative expression levels in the unstimulated cell clones. Hydrogen peroxide stimulated the upregulation of Gadd $45 \alpha$ mRNA expression in all stable FRTL 5 cell clones and the upregulation of BIM mRNA expression in the wild-type FOXO3 cells. In contrast, a trend for downregulation of $p 27^{K I P 1}$ mRNA expression was observed in all FRTL5 cell clones, but this failed to reach statistical significance. Note that the upregulation of Gadd $45 \alpha$ mRNA expression in the empty vector control is due to the endogenous FOXO3 in these cells. Furthermore, FOXOA3 mutant cells exhibited constitutive upregulation of Gadd45 $\alpha$ and BIM and showed only moderate (Gadd $45 \alpha$ ) or no further increase (BIM) after hydrogen peroxide stimulation. ${ }^{\star} P<0.03$, ${ }^{\star *} P<0.01$. 


\section{Cells with $\mathrm{FOXO} 3$ expression show upregulation of FOXO target genes BIM and Gadd45 $\alpha$ and enhanced apoptosis in response to $\mathrm{H}_{2} \mathrm{O}_{2}$}

In the next set of experiments, we wanted to explore the role of FOXO3 in oxidative stress defence in thyrocytes. To this aim, stable FRTL5 cell clones (FOXO3, FOXOA3 and empty vector controls) were treated with $0.4 \mathrm{mM} \mathrm{H}_{2} \mathrm{O}_{2}$ solution for $4 \mathrm{~h}$ and gene expression of FOXO3 target genes was measured using real-time RT-PCR. After $4 \mathrm{~h}$ treatment with $\mathrm{H}_{2} \mathrm{O}_{2}$, wild-type $\mathrm{FOXO} 3$ cell clones exhibited an increase in BIM (1.7-fold increase; Fig. 3C) and Gadd $45 \alpha$ gene expression (5.2-fold increase, $P<0.026$; Fig. 3A) compared with the untreated cells. Similarly, the FOXOA3 mutant and the control cells showed an increase in Gadd45 $\alpha$ gene expression (1.7-fold increase for FOXOA3, $P<0.026$ and 3.7-fold increase for control cells, $P<0.01$; Fig. $3 \mathrm{~A}$ ) In contrast, after $4 \mathrm{~h}$ stimulation with $\mathrm{H}_{2} \mathrm{O}_{2}$, there was a trend for downregulation of $\mathrm{p} 27^{\mathrm{KIP} 1}$ gene expression in all FRTL5 cell clones (Fig. 3B). However, this did not reach statistical significance.

Owing to the high expression of the Gadd $45 \alpha$ after $\mathrm{H}_{2} \mathrm{O}_{2}$ stimulation, we asked whether this results in induction of cell cycle arrest or apoptosis. No evidence for cell cycle arrest was found in the FRTL5 cell clones, but apoptosis was significantly increased in the FRTL5 cell clones (Fig. 4). An increase in apoptosis to $90 \%$ $( \pm 7.12, P<0.029)$ and $85 \%( \pm 3.44, P<0.05)$ of cells was observed in FRTL5 cells with stable expression of wild-type FOXO3 or the FOXOA3 mutant, respectively, on $\mathrm{H}_{2} \mathrm{O}_{2}$ exposure, while stimulation with $\mathrm{H}_{2} \mathrm{O}_{2}$ in the control cells resulted in apoptosis in $48 \%( \pm 5.79$, $P<0.029)$ cells. No increase in PI-positive necrotic cells was found after $\mathrm{H}_{2} \mathrm{O}_{2}$ exposure.

\section{Cells with FOXO3 expression show upregulation of Gadd45 $\alpha$ transcription and induction of $G_{2}-M$ cell arrest in response to UV irradiation}

In contrast to $\mathrm{H}_{2} \mathrm{O}_{2}$ stimulation, UV irradiation caused a less intense stimulation of Gadd $45 \alpha$ gene transcription (2.7-fold increase for wild-type FOXO3, $P<0.002$, 2.1-fold increase for FOXOA3 mutant, $P<0.002$, and unchanged expression for empty vector control cells; Fig. 5A). UV irradiation caused a decrease in $\mathrm{p} 27^{\mathrm{KIP} 1}$ gene expression but also a decrease in BIM gene expression in all FRTL5 cell clones (Fig. 5B and C). In contrast to $\mathrm{H}_{2} \mathrm{O}_{2}$ stimulation, UV irradiation did not result in induction of apoptosis. Since FRTL5 is not a FOXO3-deficient cell line, cell cycle analysis showed an increase in cells in $\mathrm{G}_{2}-\mathrm{M}$ phase for both wild-type FOXO3 and the empty vector

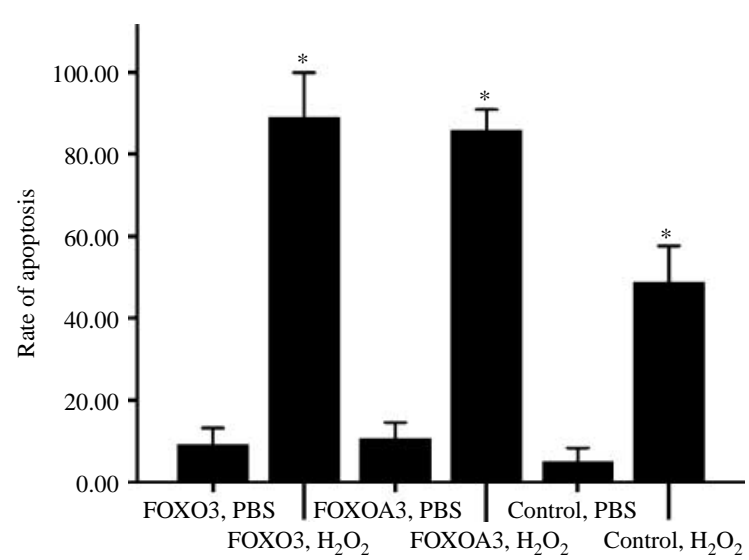

Figure $4 \mathrm{H}_{2} \mathrm{O}_{2}$ stimulation results in increased apoptosis in FRTL5 cells with FOXO3 expression. FRTL5 cell clones with stable expression of FOXO3, the FOXOA3 mutant or the empty vector (controls) was stimulated with $0.4 \mathrm{mM}$ hydrogen peroxide for $24 \mathrm{~h}$ and apoptosis was measured by double Annexin V-Cy 5/PI staining. Apoptotic cells were detected and analysed by FACS analysis. Stable expression of wild-type FOXO3 and FOXOA3 mutant led to an increase in cellular apoptosis to $90 \pm 7.12$ and $85 \pm 3.44 \%$ of cells respectively (controls: $48 \pm 5.79 \%$ ). No increase in $\mathrm{Pl}$-positive necrotic cells was detected. ${ }^{*} P<0.05$.

control cells after UV irradiation in comparison with untreated cells (Fig. 6). Subsequently, western blotting was used to determine the intracellular activation of FOXO3 and JNK signalling and the activation of the DNA damage indicator histone variant H2AX using phospho-specific antibodies.

In response to UV irradiation, stable FRTL5 cell clones (FOXO3, FOXOA3 and empty vector control cells) showed an increase in phosphorylation of $\mathrm{H} 2 \mathrm{AX}$ and JNK and a decrease in FOXO3 phosphorylation. Levels of total H2AX, JNK and FOXO3 protein expression were unchanged. Only wild-type FOXO3 cells displayed an increase in total FOXO3 protein level (Fig. 7).

\section{FOXO3 coordinates DNA damage repair in response to UV irradiation}

Increased H2AX phosphorylation is believed to reflect the presence of double-stranded DNA breaks (van Attikum \& Gasser 2009, Driessens et al. 2009). Since FOXOs coordinate multiple facets of cellular response to oxidative stress, we were interested to study the functional effect of FOXO3 on DNA damage repair in thyrocytes.

To this aim, we quantified DNA damage in FRTL5 cells with overexpression of wild-type FOXO3 and control cells transfected with the empty vector using the alkaline comet assay (Fig. 8A). In both FOXO3 and control cells, we found a strong increase in DNA 

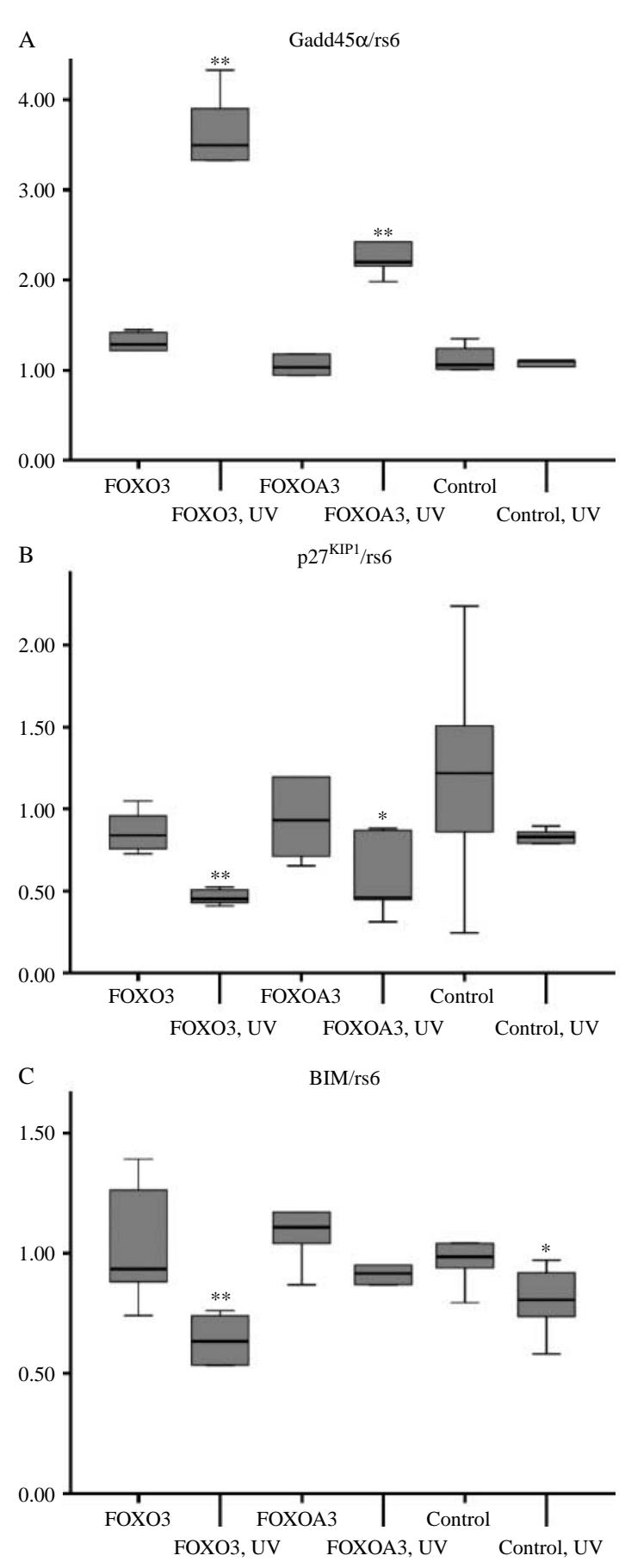

Figure 5 Gene expression in FOXO3 FRTL5 cell clones after UV irradiation. Box plots showing median and distribution of Gadd $45 \alpha(\mathrm{A})$, p2 $^{K I P 1}(\mathrm{~B})$ and BIM (C) mRNA expression in FRTL5 cell clones with stable expression of FOXO3, the FOXOA3 mutant or the empty vector (controls). mRNA expression was normalised to $r s 6$ mRNA expression. UV irradiation at a dose rate of $0.001 \mathrm{~J} / \mathrm{cm}^{2}$ led to significant upregulation of Gadd $45 \alpha$ transcription in wild-type FOXO3 and FOXOA3 mutant FRTL5 cell clones but not in control cells and resulted in downregulation of $\mathrm{p} 27^{\mathrm{KIP} 1}$ and BIM in all FRTL5 cell clones. ${ }^{\star} P<0.05$, ${ }^{\star \star} P<0.004$. damage (FOXO3 cell clones: $263.7 \pm 8.34 \mathrm{AU}$ and control cells: $249.8 \pm 0.64 \mathrm{AU}) 30 \mathrm{~min}$ after $\mathrm{UV}$ irradiation compared with the respective non-irradiated FRTL5 cell clones. Next, the kinetics of DNA damage repair was investigated over $120 \mathrm{~min}$. There was a striking discrepancy in the degree of persisting DNA damage in cells overexpressing FOXO3 compared with control cells. Thus, in FOXO3 clones, we observed a significant lower DNA damage score $(174.5 \pm 5.73 \mathrm{AU}, P<0.006) 120 \mathrm{~min}$ after UV irradiation compared with control cells, which showed an unchanged DNA damage score $(237.5 \pm 7.56 \mathrm{AU}$; Fig. 8B). This finding indicates increased repair of oxidative DNA damage via FOXO3 in the wild-type FOXO3 cell clones.

\section{Discussion}

A pivotal role of FOXO has recently been suggested in cellular defence against stressors driving carcinogenesis. FOXOs were shown to transcriptionally regulate genes directly involved in the control of cell cycle arrest, apoptosis, DNA damage repair and antioxidative defence mechanisms. Conversely, FOXO inactivation through gene alterations, impaired mRNA transcription or posttranslational FOXO modification has been found in several human cancers including thyroid malignancy (Huang \& Tindall 2007, Myatt \& Lam 2007, Weidinger et al. 2008).

In this study, we investigate the physiological role of FOXO3 in oxidative stress defence in thyrocytes. Using stable FRTL5 cell lines with expression of the wild-type FOXO3 or a constitutively activating FOXO3 mutant, which cannot be inactivated through AKT phosphorylation in response to growth factors, we demonstrate that activation of FOXO signalling slows down cellular proliferation via induction of apoptosis and is associated with altered cell morphology. In contrast, FOXO3 does not affect thyroid differentiation since expression of thyroid differentiation markers TPO and NIS was unchanged.

Furthermore, we provide evidence for a key role of FOXO3 in DNA damage response in thyrocytes using two in vitro models of oxidative stress. Hydrogen peroxide induced the transcription of the FOXO3 target genes Gadd $45 \alpha$ and BIM. Thereby cell clones with wild-type FOXO3 expression showed the highest Gadd45 $\alpha$ and BIM mRNA levels, while FOXOA3 mutant cells exhibited constitutive upregulation of Gadd $45 \alpha$ and BIM and showed no further increase after hydrogen peroxide stimulation. Furthermore, hydrogen peroxide induced apoptosis in FRTL5 cells, an effect that was dramatically enhanced in cells with 

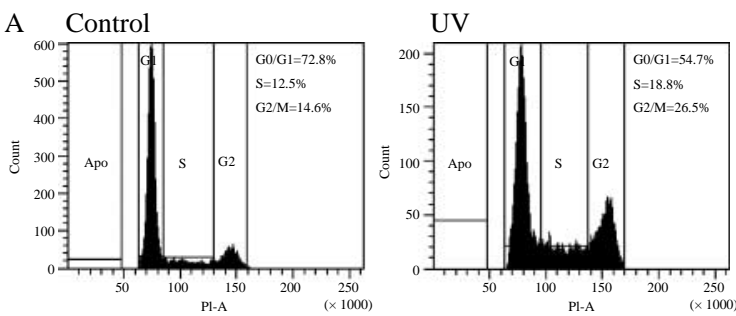

B Control
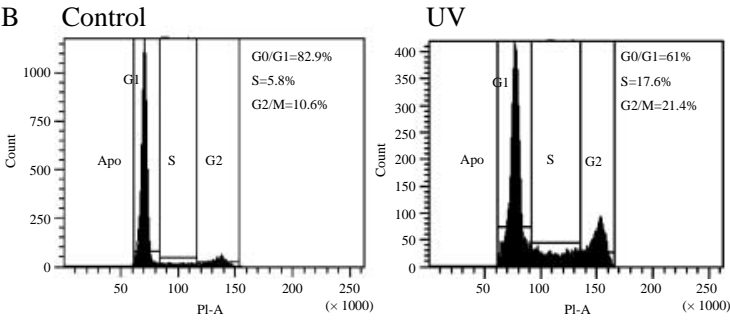

Figure 6 UV irradiation induces cell cycle arrest in FRTL5 cells with FOXO3 expression. Stable FRTL5 cell clones were exposed to a single dose of UV irradiation at a dose rate of $0.001 \mathrm{~J} / \mathrm{cm}^{2}$. Cell cycle analysis was carried out $24 \mathrm{~h}$ later by staining the nuclei with propidium iodide and performing FACS analysis of wild-type FOXO3 (A) and the empty vector control cells (B). Since FRTL5 is not a FOXO3-deficient cell line, in both cell clones, UV irradiation induced cell cycle arrest at $\mathrm{G}_{2}-\mathrm{M}$ checkpoint. Control, non-irradiated cells and UV, UV irradiation.

FOXO3 or FOXOA3 expression. In the next set of experiments, we found that UV irradiation also induced transcriptional FOXO3 activity. Thereby, UV irradiation caused a significant decrease in BIM expression in FRTL5 cells and an increase in Gadd $45 \alpha$ expression, an effect that was again significantly enhanced in cells with $\mathrm{FOXO} 3$ or FOXOA3 expression. These findings underscore the proposed functional properties of FOXO3 in thyrocytes (Weidinger et al. 2008), that is induction of apoptosis or cell cycle arrest in response to oxidative stress and activation of the DNA damage repair machinery. Of note, we observed two distinct cellular responses to the two applied genotoxic stressors: while $\mathrm{H}_{2} \mathrm{O}_{2}$ exposure led to apoptosis, UV irradiation resulted in cell cycle arrest in $\mathrm{G}_{2}$-M-phase. Gadd45 $\alpha$ target gene expression and JNK activation were present in both scenarios (Fig. 7; Karger et al. 2009).

One explanation for the distinct cellular responses may be the magnitude of oxidative stress, whereby moderate stress leads to cell cycle arrest and repair, while severe stress results in apoptosis or necrosis (Valko et al. 2007, Driessens et al. 2009). An alternative mechanism has recently been proposed by McEwen \& Pfeifer (2005) whereby the decision between cell death and survival is controlled downstream of JNK. Thus, JNK-induced cell death might be managed by a timing mechanism in which short-time activation of JNK would allow cell repair, whereas long-time activation would lead to cell death. Such a time-dependent cellular response to JNK activation is also compatible with the cellular response of FOXO3 FRTL5 cells to single-dose UV irradiation versus $24 \mathrm{~h}$ $\mathrm{H}_{2} \mathrm{O}_{2}$ exposure: single-dose UV irradiation led to an increase in cellular p-JNK, decreased p-FOXO3 (representing FOXO3 activation), DNA damage checkpoint activation $(\gamma-\mathrm{H} 2 \mathrm{AX})$ and $\mathrm{G}_{2}$-M-arrest. The rise of $\gamma-\mathrm{H} 2 \mathrm{AX}$ represents a physiological cellular response to DNA double-stranded breaks, since the histone variant $\mathrm{H} 2 \mathrm{AX}$ is rapidly phosphorylated in the chromatin microenvironment surrounding a DNA double-stranded break (Celeste et al. 2003, van Attikum \& Gasser 2009). To evaluate these DNA

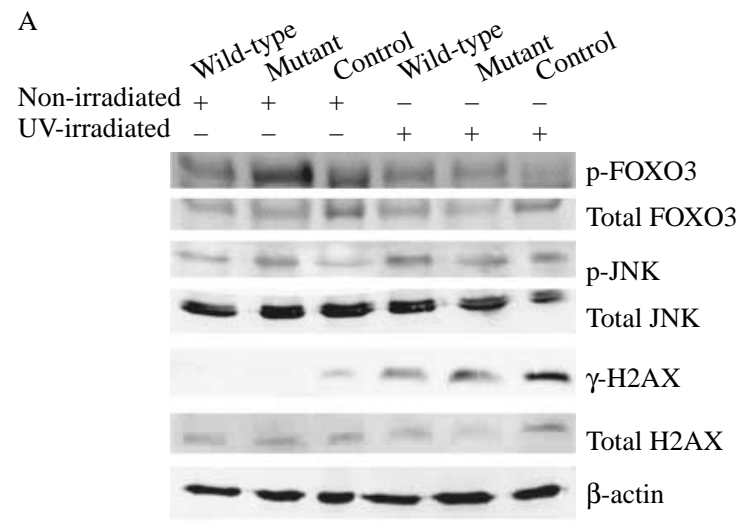

B

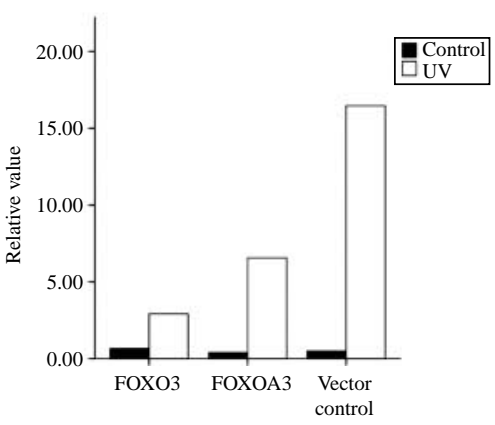

Figure 7 UV irradiation induces JNK signalling and activates the histone variant $\mathrm{H} 2 \mathrm{AX}$ in FRTL5 cells with FOXO3 expression. Stable FRTL5-cell clones (FOXO3, FOXOA3 and empty vector controls) were exposed to UV irradiation at a dose rate of $0.001 \mathrm{~J} / \mathrm{cm}^{2}$. Western blotting was carried out $8 \mathrm{~h}$ later as described in the Materials and methods section. Western blot analysis demonstrates that UV irradiation induces JNK phosphorylation and FOXO3 dephosphorylation on AKTsensitive phosphorylation sites. Furthermore, UV irradiation leads to activation of DNA damage marker $\mathrm{H} 2 \mathrm{AX}(\mathrm{A})$. Quantification of band intensity was assessed by densitometry to evaluate the ratio between phosphorylated FOXO3 and total FOXO3. The data represent the average of three independent experiments (B). Wild-type, FOXO3 wild-type; mutant, FOXOA3; and control, empty pcDNA3.1/V5-HisA vector. 
A

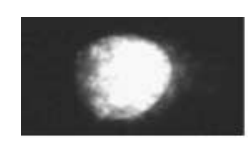

Stage 0

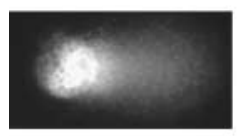

Stage 2

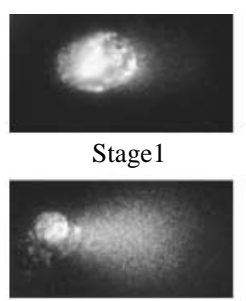

Stage 3

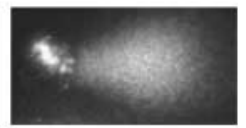

Stage 4
B

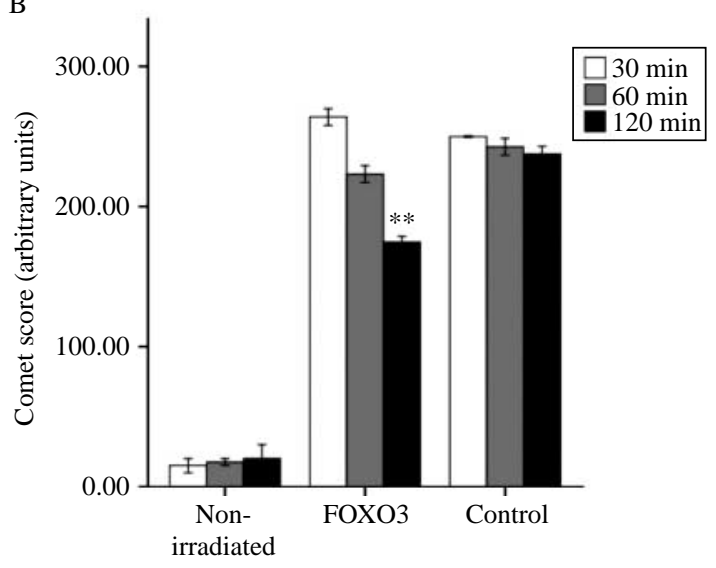

Figure 8 FOXO3 confers DNA repair in FRTL5 cells after UV irradiation. Kinetics of cellular DNA repair after UV irradiation were analysed using the comet assay in alkaline conditions. Stable FRTL5 cell clones (FOXO3, empty vector controls) were exposed to UV irradiation at a dose rate of $0.1 \mathrm{~J} / \mathrm{cm}^{2}$. At different time points $(30,60$, and $120 \mathrm{~min})$, cells were trypsinised and a comet assay was performed for analysing induction of single- and double-stranded DNA breaks. For quantification, 100 randomly selected comets on each gel were classified according to the relative intensity of fluorescence in the tail and given a value either of 0-4 from undamaged (represented by 0 ) to maximally damaged (represented by 4 ; Fig. 8A), resulting in a total score for every gel from 0 to $400 \mathrm{AU}$. Thirty minutes after UV irradiation, control and FOXO3 FRTL5 clones showed a strong increase in DNA stranded breaks. One hundred twenty minutes after irradiation, control cells showed persistent DNA damage (score of $237.5 \pm 7.56 \mathrm{AU}$ ), while FOXO3 cells showed a significant lower score of DNA damage $(174.5 \pm 5.73 \mathrm{AU})$, which indicates an increased repair of oxidative DNA damage via FOXO3 (Fig. 8B). ${ }^{* *} P<0.006$.

double-stranded breaks and the competence of FOXO3 for cellular DNA repair, a comet assay was performed. Indeed, in a time-dependent manner, wild-type FOXO3 cells showed enhanced DNA repair after UV irradiation compared with the empty vector control cells. This DNA repair pathway is most likely modulated through the Gadd $45 \alpha$ protein in the cellular response to genotoxic stress at the $\mathrm{G}_{2}$-M-checkpoint (Tran et al. 2002).

In conclusion, thyrocytes are endowed with a particularly mutagenic milieu due to endogenous $\mathrm{H}_{2} \mathrm{O}_{2}$ production during thyroid hormone synthesis and thus depend on effective defence machinery for their survival. Our results clearly demonstrate that FOXO3 plays a pivotal role in maintaining cellular integrity in defence to genotoxic agents such as hydrogen peroxide and UV irradiation. In our experiments, hydrogen peroxide conferred a strong and/or persistent genotoxic stimulus, so that the only cellular 'escape' mechanism was programmed cell death and this was markedly induced by FOXO3. UV irradiation induced a distinct cellular response, since UV irradiated cells underwent cell cycle arrest at $\mathrm{G}_{2}$-M-checkpoint allowing for DNA damage repair via FOXO activation. Impairment of these critical FOXO3 functions in the thyroid is in agreement with hallmarks of thyroid malignancy including evasion of apoptosis, loss of cell cycle control and deficient DNA damage repair.

\section{Declaration of interest}

The authors declare that there is no conflict of interest that could be perceived as prejudicing the impartiality of the research reported.

\section{Funding}

This work was supported by a Deutsche Forschungs Gemeinschaft grant (FU 356/3-1).

\section{Acknowledgements}

We thank Dr Andreas Loesche, IZKF Imaging Core Facility Leipzig, for excellent technical support and Prof. Paul Coffer, UMC Utrecht, The Netherlands, for the supply of the FOXO3 constructs.

\section{References}

van Attikum H \& Gasser SM 2009 Crosstalk between histone modifications during the DNA damage response. Trends in Cell Biology 19 207-217. (doi:10.1016/j.tcb. 2009.03.001)

Brunet A, Bonni A, Zigmond MJ, Lin MZ, Juo P, Hu LS, Anderson MJ, Arden KC, Blenis J \& Greenberg ME 1999 Akt promotes cell survival by phosphorylating and inhibiting a Forkhead transcription factor. Cell 96 857-868. (doi:10.1016/S0092-8674(00)80595-4)

Celeste A, Fernandez-Capetillo O, Kruhlak MJ, Pilch DR, Staudt DW, Lee A, Bonner RF, Bonner WM \& Nussenzweig A 2003 Histone H2AX phosphorylation is dispensable for the initial recognition of DNA breaks. Nature Cell Biology 5 675-679. (doi:10.1038/ncb1004)

Collins AR 2004 The comet assay for DNA damage and repair: principles, applications, and limitations. Molecular Biotechnology 26 249-261. (doi:10.1385/MB:26:3:249)

Driessens N, Versteyhe S, Ghaddhab C, Burniat A, De Deken X, Van Sande J, Dumont JE, Miot F \& Corvilain B 2009 
Hydrogen peroxide induces DNA single- and double-strand breaks in thyroid cells and is therefore a potential mutagen for this organ. Endocrine-Related Cancer 16 845-856. (doi:10.1677/ERC-09-0020)

Essers MA, Weijzen S, Vries-Smits AM, Saarloos I, de Ruiter ND, Bos JL \& Burgering BM 2004 FOXO transcription factor activation by oxidative stress mediated by the small GTPase Ral and JNK. EMBO Journal 23 4802-4812. (doi:10.1038/sj.emboj.7600476)

Huang H \& Tindall DJ 2007 Dynamic FoxO transcription factors. Journal of Cell Science 120 2479-2487. (doi:10. 1242/jcs.001222)

Karger S, Weidinger C, Krause K, Sheu SY, Aigner T, Gimm O, Schmid KW, Dralle H \& Fuhrer D 2009 FOXO3a: a novel player in thyroid carcinogenesis? EndocrineRelated Cancer 16 189-199. (doi:10.1677/ERC-07-0283)

Knauf JA \& Fagin JA 2009 Role of MAPK pathway oncoproteins in thyroid cancer pathogenesis and as drug targets. Current Opinion in Cell Biology 21 296-303. (doi:10.1016/j.ceb.2009.01.013)

Krause K, Karger S, Schierhorn A, Poncin S, Many MC \& Fuhrer D 2007 Proteomic profiling of cold thyroid nodules. Endocrinology 148 1754-1763. (doi:10.1210/en.2006-0752)

Krohn K, Führer D, Bayer Y, Eszlinger M, Brauer V, Neumann S \& Paschke R 2005 Molecular pathogenesis of euthyroid and toxic multinodular goiter. Endocrine Reviews 26 504-524. (doi:10.1210/er.2004-0005)

Krohn K, Maier J \& Paschke R 2007 Mechanisms of disease: hydrogen peroxide, DNA damage and mutagenesis in the development of thyroid tumors. Nature Clinical Practice. Endocrinology \& Metabolism 3 713-720. (doi:10.1038/ ncpendmet0621)

Maier J, van Steeg H, van Oostrom C, Paschke R, Weiss RE \& Krohn K 2007 Iodine deficiency activates antioxidant genes and causes DNA damage in the thyroid gland of rats and mice. Biochimica et Biophysica Acta 1773 990-999. (doi:10.1016/j.bbamcr.2007.03.011)

McEwen DG \& Pfeifer M 2005 Puckered, a Drosophila MAPK phosphatase, ensures cell viability by antagonizing JNK-induced apoptosis. Development 132 3935-3946. (doi:10.1242/dev.01949)
Myatt SS \& Lam EW 2007 The emerging roles of forkhead box (Fox) proteins in cancer. Nature Reviews. Cancer 7 847-859. (doi:10.1038/nrc2223)

Nikiforova MN, Stringer JR, Blough R, Medvedovic M, Fagin JA \& Nikiforov YE 2000 Proximity of chromosomal loci that participate in radiation-induced rearrangements in human cells. Science 290 138-141. (doi:10.1126/science.290.5489.138)

Sinnott B, Ron E \& Schneider AB 2010 Exposing the thyroid to radiation: a review of its current extent, risks, and implications. Endocrine Reviews 31 756-773. (doi:10. 1210/er.2010-0003)

Song Y, Driessens N, Costa M, De Deken X, Detours V, Corvilain B, Maenhaut C, Miot F, Van Sande J, Many M-C et al. 2007 Roles of hydrogen peroxide in thyroid physiology and disease. Journal of Clinical Endocrinology and Metabolism 92 3764-3773. (doi:10. 1210/jc.2007-0660)

Tran H, Brunet A, Grenier JM, Datta SR, Fornace AJ Jr, DiStefano PS, Chiang LW \& Greenberg ME 2002 DNA repair pathway stimulated by the forkhead transcription factor FOXO3a through the Gadd45 protein. Science 296 530-534. (doi:10.1126/science. 1068712)

Valko M, Leibfritz D, Moncol J, Cronin MTD, Mazur M \& Telser J 2007 Free radicals and antioxidants in normal physiological functions and human disease. International Journal of Biochemistry \& Cell Biology 39 44-84. (doi:10.1016/j.biocel.2006.07.001)

Weidinger C, Krause K, Klagge A, Karger S \& Fuhrer D 2008 Forkhead box-O transcription factor: critical conductors of cancer's fate. Endocrine-Related Cancer 15 917-929. (doi:10.1677/ERC-08-0153)

Received in final form 26 June 2011

Accepted 28 June 2011

Made available online as an Accepted Preprint 28 June 2011 